\title{
Review
}

\section{Large-scale hepatitis C combating campaigns in Egypt and Georgia; past, current and future challenges}

\author{
Fatma Abdelaziz Amer ${ }^{1}$ \\ ${ }^{1}$ Department of Medical Microbiology and Immunology, Faculty of Medicine, Zagazig University, Zagazig, Egypt
}

\begin{abstract}
Hepatitis $\mathrm{C}$ virus (HCV) infection is a major worldwide problem which should be adequately combated. This review summarizes two successful model programs to eradicate Hepatitis C in two countries; Egypt and Georgia. Egypt tops the list of nations affected by HCV, and Georgia is ranked among other countries with huge HCV burden. Currently, both countries are on their ambitious way to making history and completely eliminate Hepatitis $\mathrm{C}$ virus infections.

The first comprehensive approach to reduce the burden of hepatitis $\mathrm{C}$ and associated diseases in Egypt was achievable with the formulation of the National Committee for Control of Viral Hepatitis (NCCVH) in 2006. Assisted by international and national stalk holders, Georgia started its nation- wide HCV fighting program in 2015. Elements of programs mostly addressed in both countries included simplifying and improving access to the package of diagnosis and care- providing effective, affordable or free of charge treatment- issuing, applying and regularly updating practice guidelines- improving surveillance, monitoring, and research focusing specifically on the risky groups- emphasizing infection control (IC) - encouraging patient and community engagement and increasing public and political commitment. Interventions are still going on to eradicate HCV infection in Egypt by 2030 and in Georgia by 2020. Lessons gained from these programs can educate comparable activities in different nations and help control the worldwide epidemic of viral hepatitis.
\end{abstract}

Key words: Hepatitis C virus; Egypt; Georgia, direct acting antivirals.

J Infect Dev Ctries 2018; 12(6):404-414. doi:10.3855/jidc.9784

(Received 26 September 2017 - Accepted 07 June 2018)

Copyright $(2018$ Amer. This is an open-access article distributed under the Creative Commons Attribution License, which permits unrestricted use, distribution, and reproduction in any medium, provided the original work is properly cited.

\section{Introduction}

Hepatitis $\mathrm{C}$ virus (HCV) affects an estimated number of 71 million people. In spite of being a world epidemic, there is excessive geographic variability. Among key countries which are being highlighted for their innovative work to eliminate viral hepatitis are Egypt and Georgia. Egypt is located in North Africa, with a long Mediterranean coast. It has an area of more than one million square kilometers, with over 93 million inhabitants. Georgia is located in the Caucasus region of Eurasia. It covers a territory of about 70,000 square kilometers with about 3.72 million inhabitants. Hepatitis C viral infection is endemic in Egypt. Almost, each family is touched by the malady. The crusade against schistosomiasis which started in 1950 and ended in 1980 is the most acknowledged evidence of the presence of the large pool of chronic HCV infection [1]. Furthermore, hazardous blood transfusion and unsafe injection procedures were blamed for $24.3 \%$ and $20.6 \%$ of HCV-positive cases, respectively. Breaches in infection control (IC) at both hospital and community levels, as well as the possibility of household transmission are other contributing risk factors [2]. In
Georgia [3], albeit unsafe injection and blood safety techniques add to the $\mathrm{HCV}$ disease burden, injection of drugs is the most significant calculated hazard. A disease rate of $70 \%$ was noted among people who inject drugs (PWID). The pervasiveness of HCV disease is high among prisoners (50\%) and people infected with human immunodeficiency virus (HIV) (47\%). Poor adherence to IC policies and procedures is also a remarkable causative component.

\section{The Burden of HCV}

Egypt

In 2015, the Egyptian Health Issues Survey (EHIS) was carried out to re-estimate the prevalence of $\mathrm{HCV}$ infection after the previous two nationwide surveillances in 1996 and 2008. The highest prevalence occurred along the river Nile with genotype 4 being the predominant. In the age group 15-59-years, hepatitis C virus antibody $(\mathrm{HCV} \mathrm{Ab})$ prevalence was $10.0 \%$, and HCV RNA at $7.0 \%$, while in the age group 1-14 year, the prevalence of $\mathrm{HCV} \mathrm{Ab}$ was $0.4 \%$, and HCV RNA at $0.2 \%$ [4]. There is an estimated 150,000 new infections/year. Chronic HCV is the chief cause of liver 
cirrhosis and liver cancer, and is the most common indication for liver transplantation and one of the top five leading causes of death in Egypt. It kills an estimated 40,000 Egyptians a year [5]. The Hepatitis C Model of Care (MOC) in Egypt is the largest nationally funded program and makes almost $20 \%$ of the Ministry of Health and Population's (MOHP's) budget of 90 Million US\$ [6].

\section{Georgia}

According to the Georgia National Survey conducted in 2015, the prevalence of HCV antibodies among the general population was $7.7 \%$ and $5.4 \%$ tested positive for HCV RNA [7]. The seroprevalence among PWID was 57-92\%, amid homosexual men was $17 \%$ and amongst healthcare workers (HCW) was 4 $12 \%$ [3]. Injection-drug use is a striking general medical issue and has expanded the HCV epidemic through shared utilization of needles, syringes, and other infusion equipment among the assessed 50,000 PWID living in Georgia [8]. Different gatherings of people who might be in danger for $\mathrm{HCV}$ incorporate men who engage in sexual relations with men (MSM) (dependent on the city, prevalence ranging from $7.1 \%$ to $18.9 \%$ ) and blood donors. Prisoners additionally have higher rates. Testing amid 2004- 2008 revealed $52 \%$ anti- HCV positivity among 2,031 detainees in confinement offices [3]. Genotype 1 accounted for $43 \%$ of $\mathrm{HCV}$ infection, genotype 3 for $37 \%$ and genotype 2 for the remaining $20 \%$ of cases. NS5B and 5'UTR/Core sequencing studies indicated that more than half of $\mathrm{HCV}$ genotype 2 patients in Georgia are infected with $2 \mathrm{k} / \mathrm{lb}$ recombinant strain [9]. This strain is one of the natural intergenotypic recombinant forms that have genotype 2 sequences in the structural regions and genotype 1,5 or 6 sequences in the nonstructural regions [10].

\section{Large-scale Hepatitis C Combating Campaigns Egypt}

Combating the HCV epidemic, with its high prevalence in Egypt is a demanding task. It necessitated establishing a novel MOC to contain the epidemic, provide patient care and access to global treatment [6]. It is worth mentioning that fighting HCV in Egypt dates back to 1994. After the discovery of HCV in 1989 by Michael Houghton and co- authors and based on studies showing that $10 \%$ of 2,164 blood donors were HCV carriers [11], Egypt's Parliament was compelled to mandate screening of blood bank donors.

In 2006 and in response to the massive $\mathrm{HCV}$ problem, the MOHP convoked the NCCVH to set up and implement a national control program of HCV and other causes of hepatitis aiming at eradication of the disease by 2030. In spite of the recognition of the severity of the HCV burden in Egypt lagging several years, the HCV MOC only came into action with the establishment of the NCCVH. The advisory board members of the Committee are made of Hepatology and Public Health Professors in Egyptian Universities, an MOHP representative, and ad hoc experts from the Pasteur Institute in Paris, France, and the University of California in San Francisco, USA. The later foreign experts were included at the initial phase of NCCVH functions [12]. The strategy of the NCCVH is summarized as: 1) providing affordable/free of charge and accessible HCV therapy to any one suffering from the disease who is evaluated and clinically prioritized after on- line registration, 2) preparing treatment protocols and guidelines, 3) training healthcare teams, 4) monitoring the HCV disease burden on an on-going basis, 5) developing a national data base by centralizing electronic medical records from all treatment centers, analyzing data and providing feedback to service providers, 6) negotiating prices of medicines for the MOHP- supported program, 7) boosting carrying out of high quality research in all aspects related to $\mathrm{HCV}$ infection, 8) supporting IC and 9) enhancing public awareness campaigns [12]. Working for the first strategy, it was important to reduce the price and expand government subsidization. At the early stage of $\mathrm{HCV}$ fighting programs, treatment was based on standard of care (SOC) medications; pegylated interferon and ribavirin "pegINF/R". Enhancing the local production of SOC medications led to a sharp price reduction (around US\$40/week vs. 208- 416 US\$ for the innovator products) [13].

In 2007, the NCCVH established $26 \mathrm{HCV}$ treatment centers in MOHP- affiliated healthcare facilities throughout Egypt in order to augment the accessibility to HCV treatment. Centers were set to be geographically evenly distributed, so that patients would not need to travel more than 50 kilometers to reach a treatment center. The centers are managed by well-trained teams of hepatologists offering a full range of care, beginning with preliminary screening up to providing proper treatment according to standardized SOC- based protocols. The centers were planned to treat 360,000 patients till 2014. More than 54 centers were established between 2007- 2015 and managed by 2000 trained staff providing care and treating to nearly 800,000 chronic HCV- infected patients. Nationwide treatment centers are on an on-going effort for scaling up, to reach 100 by the end of 2017 [5]. 
The year 2008 marked the launch of the "National Control Strategy for Viral Hepatitis", a state plan to target viral hepatitis [12]. In the same year, enhanced by NCCVH, HCV testing was integrated in the 2008 National Demographic Health Survey (DHS) [14].

In 2010, assisted by the Academy of Scientific Research and Technology (ASRT), the National Network for Treatment Centers (NNTC) was formed with the objective of larger capacity building for data management. It is a virtual private network (VPN) connecting nationwide centers to the head office. The main server is located in the National Hepatology Institute in Cairo; it then had full data of pre-enrollment and treatment of $>350,000$ patients [15].

As of 2011, direct acting antivirals (DAAs) for treatment of HCV emerged as the final nail in the coffin. On December $6^{\text {th }}, 2013$, sofosbuvir, the pangentopic drug with a high barrier for resistance was approved by the Food and Drug Administration (FDA). Egypt with its huge HCV burden was not foreign to this modality. After hard work, sound scientific research and extensive negotiations between the Egyptian

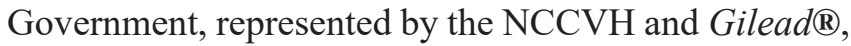
a new era started in Egypt in 16 October 2014, when sofosbovir was first introduced. The Egypt/ Gilead agreement determined that the cost of a 3-months course was 900 US\$ instead of 84000 US\$ in the USA. The agreement also stated that: sofosbovir would be manufactured for use in Egypt with a different color and labeled (to be sold only in Egypt), agreement would be renewed yearly, sofosbovir would be available (on a fast track) after the registration process was completed [16]. Three months earlier, in July 2014, the new sofosbovir- based Egyptian HCV Management Guidelines were established for HCV G4 treatment [17]. The existence of program infrastructure and the tightly supervised system capable of preventing diversion of medication to other countries, the availability of a national $\mathrm{HCV}$ database, in addition to the huge burden of HCV infection in Egypt positively contributed to the success of negotiations. Due to the fact that prices were set in local currency equivalent, with the current devaluation of local currency, the prices in USD decreased by $50 \%$ [6]. The deal with "Gilead Sciences" set the bar for the cost of introducing new DAAs to Egypt. Subsequent negotiations with other DAAs manufacturers resulted in the availability of more antivirals at reduced price in 2015. Examples are "Semiprevir" (Janssen Pharmaceutica, Beerse, Belgium) and "Daclatasvir" (Bristol-Meyers-Squibb, New York City, NY, USA) at $\$ 1000$ for a 12 -week course each vs. 66000 and 63000 US\$ in the US respectively, and Sofosbuvir- Ledipasvir (Gilead Sciences, Foster City, California, USA, U.S.A.) for the equivalent of US $\$ 1600$ for a 12-week course vs. 94,000 US\$ in the US [18]. In addition to the agreements signed with the international pharmaceuticals of the innovative brands, MOHP, as well as other official bodies, contracted with further corporations to manufacture the DAAs locally. Currently, many DAAs are available in Egypt. Guidelines for various categories of Egyptian HCV patients have been developed by the NCCVH and is being regularly updated, see Table 1 [19]. Treatment centers are functioning and treating HCV - infected patients through a financial system depending on governmental support of ca. $59 \%$ of patients, as well as the Health Insurance Organization (HIO) covering $29 \%$. The remaining $12 \%$ of patients paid for their treatment costs at the reduced price [4].

A series of programs reinforced by the NCCVH is being implemented consisting of: screening program of hepatocellular carcinoma among high-risk groups, and control of hepatitis B virus (HBV) infection program. Studying the management of children with chronic $\mathrm{HCV}$ infection which are carried out by the Egyptian Liver Care Society; a non- governmental organization (NGO) and supervised by the NCCVH [6].

The outcome of all previously mentioned efforts is the drop-in percentage in the 15- 59 age group testing positive for HCV Ab. In 1996, the percentages of men

Table 1. Guidelines of the National Treatment Program in Egypt [19].

\begin{tabular}{|c|c|c|c|}
\hline $\begin{array}{l}\text { Easy to treat } \\
\text { (12 weeks) }\end{array}$ & $\begin{array}{l}\text { Not easy to treat } \\
\text { (12 weeks) }\end{array}$ & $\begin{array}{l}\text { Advanced liver disease (child B) } \\
\text { (12 weeks) Only in centers }\end{array}$ & $\begin{array}{l}\text { Post transplantation } \\
\text { (24 weeks) }\end{array}$ \\
\hline Sofo+ Dacla & Sofo + Dacla + R & Sofo + Dacla + R & Sofo+ Dacla \\
\hline Sofo+ Sime & Sofo + Sime & $\mathrm{Sofo}+\mathrm{Ldv}+\mathrm{R}$ & Sofo+ Ldv \\
\hline Sofo + Ldv & Sofo $+\mathrm{Ldv}+\mathrm{R}$ & & \\
\hline \multirow[t]{3}{*}{$\mathrm{Obv} / \mathrm{Ptv} / \mathrm{r}$} & $\mathrm{Obv} / \mathrm{Ptv} / \mathrm{r}$ & & \\
\hline & Dose of $\mathrm{R}$ is $600 \mathrm{mg} /$ day & Dose of $\mathrm{R}$ is $600 \mathrm{mg} /$ day & \\
\hline & $\begin{array}{l}\text { Trial should be done to } \\
\text { reach a dose of } 1000 \mathrm{mg} / \text { day } \\
\text { based on tolerability }\end{array}$ & $\begin{array}{l}\text { Trial should be done to reach a dose of } \\
1000 \mathrm{mg} / \text { day based on tolerability }\end{array}$ & \\
\hline
\end{tabular}


and women who tested positive for $\mathrm{HCV} \mathrm{Ab}$ were $25.8 \%$ and $20.1 \%$ respectively, versus $16.6 \%$ and $11.8 \%$ in 2008 , and $12 \%$ and $9 \%$ in 2015 . There was an overall significant decrease of $32 \%$ to $29 \%$ in the prevalence of HCV antibody and HCV RNA-positive individuals, respectively, between the DHS in 2008 [14] and the EHIS in 2015 (Figure 1) [20].

\section{Georgia}

The Georgian National HCV Elimination Program was launched in April 2015 with the contribution of: the Government of Georgia- Gilead Science- Global Fund to Fight AIDS, Tuberculosis, and Malaria (GFATM); Center for Disease Control and Prevention (CDC); Liver Institute and Foundation for Education and Research (L.I.F.E.R.); National Center for Disease Control (NCDC); Ministry of Labour, Health and Social Affairs of Georgia (MoLHSA); Project ECHO (Extension for Community Healthcare Outcomes); Scientific Committee of the National Hepatitis C Elimination Program; Infectious Diseases, AIDS and Clinical Immunology Research Center; and all HCV Care Providers. The target of the overall program is summarized as $90 / 95 / 95$; meaning that by $2020,90 \%$ of Georgians living with HCV will be diagnosed, 95\% of them will be treated and $95 \%$ of those treated will be cured. Achievement of these goals is expected to reduce mortality by at least $65 \%$ [3]. Nevertheless, diagnosis of HCV started as early as 1997 . Coordinated by state programs, HCV rapid testing was conducted for HIVinfected patients [21], for blood donors [22] and for PWID [23-24]. On the other hand, providing HCV treatment with SOC regimen at small scales began in 2011. A Free of Charge Treatment Program was offered for a limited number of HIV/HCV co-infected persons. As of July 2015, 428 individuals received treatment [25]. In 2013, the State Program of Free of Charge Hep C Treatment for prisoners was initiated and as of July 2015, 406 detainees received treatment. In 2014, the Georgian government negotiated extra 10,000 treatments with reduced price for civil population followed by the initiation of a $60 \%$ reduction program. As of July 2015, 851 patients received treatment [25].

In 2014, Georgia connected with accomplices to develop a comprehensive HCV prevention and control plan; the idea of disposal of HCV transmission and infection developed amid a gathering with them. To plan for the launch of an HCV eradication program, Georgia asked for help from the US CDC to 1) conduct a national survey, 2) assess laboratories and health care providers and 3) monitor and evaluate the program [25]. A National Commission for $\mathrm{HCV}$ elimination campaign
Figure 1. Inclines in the percentage of population age 15-59 testing positive $\mathrm{HCV} \mathrm{Ab}$ in the three surveillances conducted in Egypt; 1996, 2008 and 2015. Adapted from Kandeel et al. [20].

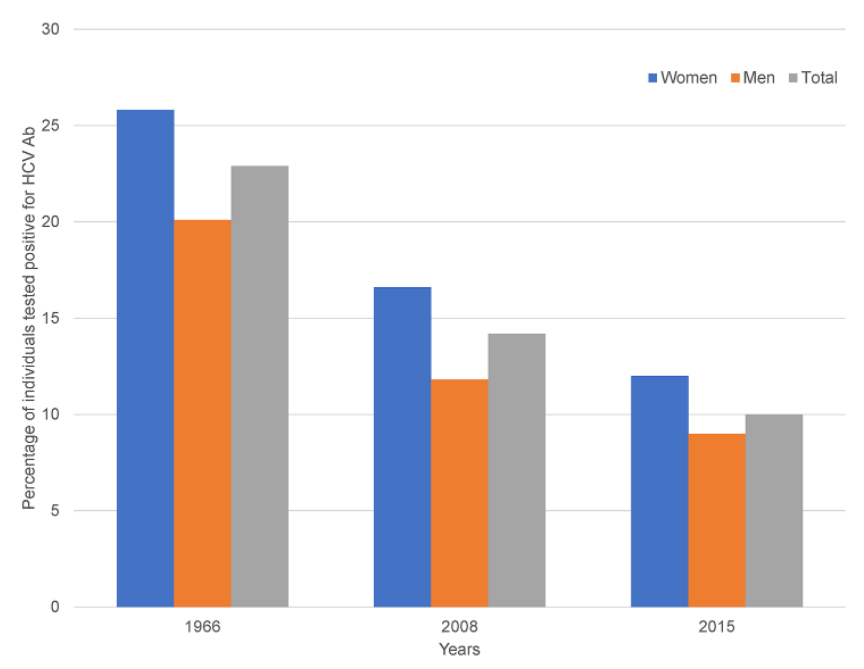

was established and convened the $1^{\text {st }}$ Workshop, whereas its $2^{\text {nd }}$ Workshop was held in 2015 [3]. The Historical Day, April $21^{\text {st }} 2015$, witnessed the signing of a Memorandum of Understanding between Georgia Government and Gilead to donate DAAs' HCV medications. A preliminary phase (Phase I) of $\mathrm{HCV}$ eradication program was designed to be implemented (April 2015-April 2016) [7].

In May 2015, the national and population-based survey of hepatitis B and hepatitis $\mathrm{C}$ prevalence and risk factors was launched in Tbilisi, five major cities and 10 rural regions. The sample size was 7,000 adults. Laboratory investigations included $\mathrm{HCV} \mathrm{Ab}$ testing as well as HCV RNA analysis. An HCV Elimination Program Treatment Inclusion Committee was established consisting of patient advocacy representatives, clinicians and media. Its function was to supervise the process of treatment access. A data management system (STOP-C) was developed which allowed data entry by health care providers and the Central Social Service Agency based at MoLHSA in Tbilisi [3]. Four of the top- listed clinical sites in Tbilisi were selected as initial pilot sites for the program.

During phase I of the program, a total of 27,392 patients having positive $\mathrm{HCV} \mathrm{Ab}$ test results were enrolled, 27,155 (99.1\%) initiated diagnostic workup and a total of 9,615 (36.3\%) completed examinations. Degree of hepatic fibrosis was determined using FIB-4 score and ultrasound or transient elastography [7,26]. Treatment was provided for $8,448(87.9 \%)$ patients most of them were having advanced liver disease and at highest risk for complications [3]. Treatment regimens were either sofosbovir in combination with SOC 
$(33.9 \%)$ or Sofosbovir plus Ribavirin (45.4\%). Outcome data for patients treated through April 2016 indicated that SVR was achieved in $82.6 \%$.

On November 3-4, 2015, MoLHSA teamed up with 11 national and international specialists in the field of viral hepatitis from $\mathrm{CDC}$, WHO and other worldwide partners to assemble the first external Hepatitis Technical Advisory Group (TAG) meeting. The formation of TAG was a groundbreaking stage in fighting $\mathrm{HCV}$. One of the key proposals coming out from TAG meeting was to develop an Elimination Plan. A draft strategy was set, reviewed and discussed [3]. In mid-February 2016, Gilead Sciences started free offering of the recent DAA combination medicate; Sofosbuvir/Ledipasvir [7]. In the spring of the same year data analysis of the population-based serosurvey was accomplished. A number of the key indicators of the eradication strategy was altered based on reorganized prevalence information. The monitoring and evaluation outline was more deeply discussed during the 3rd National Hepatitis C Workshop held in Tbilisi, Georgia, on April 6-8, 2016. On June 18, the L. I. F. E. R. symposium for the Elimination Program was made, followed by the formation of the National Working Group at NCDC. The membership of the later included national stakeholder as well as the highly distinguished local experts. International partners provided input to promote configuration of the strategies with best-practice guidelines and standards. Working all together, the results were the final version of the Elimination Plan with well-conceived and comprehensive goals, strategies, objectives, and proposed activities. It is anticipated that the plan will be revised as challenges emerge. Strategies of the national HCV Elimination Plan are 1: promote advocacy, awareness and education, and partnerships for HCVassociated resource mobilization, 2: prevent $\mathrm{HCV}$ transmission, 3: identify persons infected with $\mathrm{HCV}, 4$ : improve $\mathrm{HCV}$ laboratory diagnostics, 5: provide $\mathrm{HCV}$ care and treatment, 6: improve HCV surveillance [3].

By December 2016, the number of treatment centers had increased to 27 . From the start of that month, investigations showed that $30,046(78.8 \%)$ out of 58,223 persons with positive $\mathrm{HCV} \mathrm{Ab}$ results were confirmed as chronic patients. After completing the diagnostic workup, 27,595 (91.8\%) began treatment. The treatment criteria were expanded to allow treatment for all individuals with HCV infection (beginning June 1 through December 31, 2016). By the end of December, a total of 19,778 persons completed treatment; $75 \%$ were treated by Sofosbuvir/Ledipasvir and $25 \%$ received Sofosbovir- based regimens. Out of
6,366 (32.2\%) eligible patients, SVR was achieved by $5,356 \quad(84.1 \%)$ persons. Response to Sofosbuvir/Ledipasvir- based regimens was much higher than that of Sofosbovir-based treatments [27].

\section{Prevention}

Limited compliance with IC occurs whether inhospital or in community settings which facilitates the transmission of $\mathrm{HCV}$ in both countries.

Egypt

Presumably, unsafe parenteral injection techniques are the most important. The average number of injections/person/year for various indications in Egypt is 6.8 compared to 2.88 globally. Out of 281 million injections performed every year, 23 million $(8 \%)$ are considered unsafe [28]. In hospital settings, other procedures, blood transfusion, and dental treatment have been incriminated in $\mathrm{HCV}$ transmission [4]. Health care workers (HCW) are at a risk of occupational acquisition of the infection, primarily due to accidental needle stick injuries. HCW experience 4.9 needle stick injury/worker compared to 1.2 /worker globally [28]. In community settings, social and cultural factors are important contributors to $\mathrm{HCV}$ transmission and the importance of intrafamilial and sexual transmission has been highlighted [2].

In 2001, when the "National Infection Control Program" was launched, emphasis was placed on minimizing transmission of blood- borne infections including HCV. The program stressed safe injection practices and adherence to Standard Precautions. In 2002, another nation- wide program was implemented in Egypt as a result of collaboration between MOHP, Naval Medical Research Unit Three (NAMRU-3) and WHO. Accordingly, an organizational IC structure was established in many healthcare facilities, IC guidelines were developed, training of HCWs was provided, occupational safety was promoted, and a system for monitoring and evaluating IC activities was inaugurated [29]. This plan was applied in MOHP facilities and primary care centers. By 2003, IC programs were established in 450 MOHP facilities. In 2011 International Health Regulations assessment revealed substantial reduced iatrogenic transmission of $\mathrm{HCV}$. For example, the annual incidence of HCV infection among dialysis patients declined from $28 \%$ to $6 \%$. Improvements also were concluded in $\mathrm{HCWs}$ compliance with Standard Precautions [30].

One of the six topic areas which organize the Egyptian Viral Hepatitis Plan of Action, 2014- 2018 [14] is curbing hepatitis C virus spread in Egypt by 
promoting IC in all types of healthcare facilities. Community cannot be ignored in a nation- wide program, which is of a particular concern to specific groups, including persons at high risk for infection and those who perpetuate transmission of $\mathrm{HCV}$ to others (e.g., HCV infected patients and their family members, barbers, non-certified injection providers, dentists, and pharmacists). The plan stressed the necessity of increasing public awareness of viral hepatitis prevention and promoting safe parenteral injection practices. Large scale campaigns have been launched involving multi- sectorial approach at both public and official levels. Awareness crusades were carried out throughout the country. They were funded by the Egyptian Ministry for Scientific Research, MOHP, private sector, civil society, UNICEF and WHO. The media contributed greatly to enlighten the problem of $\mathrm{HCV}$ infection; how to avoid, how to register and how to get access to treatment if proved to be seropositive. The highest awareness impulse was provided when the Egyptian President spoke publicly about battling HCV and stressed that "it is a national priority ". The efforts of Egypt were acknowledged by the WHO selection of Egypt, as one of the three countries to be supported for the global injection safety program, and celebrating the Global World Hepatitis Day in 2015 in Egypt [31].

\section{Georgia}

On developing the Elimination Plan, excessive stress was put on raising awareness of viral hepatitis and prevention. Raising awareness activities will be monitored on an ongoing basis by the Public Relations Group within the NCDC health promotion division. The same NCDC group will lead execution of actions directed to high- level state strategy producers, HCWs, and other significant gatherings to reduce stigma and discrimination related to hepatitis [32].

Preventing the occurrence of new HCV infections among PWID is planned to be achieved by struggling across several cross-cutting areas. PWID are given effective harm-reduction services and linkages to HCV treatment. In 2001, supported by GFATM, Georgia initiated harm reduction services by establishing 14 Needle and Syringe Program (NSP) drop-in centers in 11 cities. Coordinated by the network of communitybased organizations (Georgian Harm Reduction Network), these centers provide a basic package of services, including distribution of sterile injection equipment; voluntary counseling and testing (VCT) for $\mathrm{HIV}, \mathrm{HCV}, \mathrm{HBV}$, and syphilis; distribution of safe sex information and prophylactics and overdose prevention [23]. Peer Driven Intervention (PDI) methodology [33] was introduced in 2010 to boost the education-focused activities. In 2014, PDI was complemented by community-based outreach services. Within the GFATM project, four mobile laboratories were procured to expand the geographic coverage. In 2016 two more mobile laboratories were procured, increasing the number of cities with access to VCT to 55. According to NSP program data, HCV testing rates have dramatically increased in the last few years likely as a result of such efforts [3].

Georgia launched its State Safe Blood Program (SSBP) aiming at increasing the availability of safe blood through increasing the non-remunerated donations as well as ensuring proper screening before donation [34]. Twelve out of the total of 18 blood banks in the country participated in the program and are licensed to collect blood and blood components. In 2011 blood banks involved in the SSBP were under the umbrella of technical supervision for the Transfusion Transmissible Infections (TTIs) by the NCDC's Lugar center (a biosafety Level [BSL] 3 laboratories established with support from the U.S. government). By 2014 there was significant increased average number of donations of which $30 \%$ were from voluntary donors. In 2015, blood banks participating in the SSBP were required every 3 months to perform quality control through contracted international reference laboratories [3].

IC programs and nosocomial infection surveillances are implemented at a small scale in healthcare facilities [35]. Compliance is monitored and regulations are enforced by the Agency for State Regulation of Medical Activities. MoLHSA's Department of Health Care, State Regulation Agency for Medical Activities and NCDC are currently working to expanding IC committees and to ensure the availability of functioning programs in all facilities. Moreover, State regulations/policies for IC during aesthetic and cosmetic procedures performed in nontraditional healthcare and other community settings will be developed and enforced [3].

\section{Challenges}

Egypt

With the first introduction of DAAs in Egypt in 2014, a critical problem was to organize and simplify evaluation, prioritization and treatment of nearly 750000 patients diagnosed and requiring treatment in the then- available 26 specialized centers. The problem could have been solved by the inauguration of additional centers [4]. The Ministry of State for Administrative Affairs made a great contribution, by 
establishing a web- based online registration system [12] which was custom-developed for the first time in the healthcare setting in Egypt. The system allows the highest possible submissions per second. After, online appointments were scheduled and automatically set to the center closest to each patient on a vacant priority basis. Scheduled lists were posted online and at the treatment centers. The process was supported by the Ministry of Communication which provided easy access to the portal and offered mobile phone messaging service via SMS for faster patient contact. Moreover, helplines were established to answer patients' queries. At the time of introduction of DAAs to Egypt, the waiting time was up to 6 months or more. By the end of November 2016, nearly 1,500,000 patients registered and appointments were set the same week [6].

In spite of the fact that IC programs were actualized in most MOHP facilities and primary care centers, these are not the only providers of HCV patient management. Others include: university hospitals, military and police facilities. The private sector's contribution (basically private clinics and centers and drug stores) is highly important. In light of this information, effective development of IC programs should include these settings.

In order to control HCV and its complications and drastically lessen the predominance and burden of $\mathrm{HCV}$ in Egypt, strategies going towards expanding diagnosis and treatment, together with avoiding transmission are required. In the event that compelling measures are not embraced to lessen occurrence, and number of new cases just declines as an impact of expanded cure, there will be 1 million more cases by $2030(1,250,000$ versus $285,000)$, and sickness end would not be achieved as expected (Figure 2) [16].

\section{Georgia}

The predominance of the strain $2 \mathrm{k} / 1 \mathrm{~b}$ in Georgia is challenging. The first of these recombinants, RF2k/1b, was identified in Russia [36], since then it has been described in patients from other countries [10,37-40 ]. Even if infection with this type is wide-spread, most of the diagnosed patients were infected in Georgia through either injection drug use or sexual contact, suggesting that this recombinant virus is circulating in this country. Advanced genotyping procedures are needed because conventional assays document such genotype as genotype 2 or mix 1 and 2 . If patients are treated accordingly, the occurrence of SVR is low.

The present hepatitis C surveillance system isn't adequate for evaluating the overwhelming burden of
$\mathrm{HCV}$ in Georgia [3]. For the purpose of upgrading its capability, the communicable diseases surveillance system in Georgia and the Electronic Integrated Disease Surveillance System (EIDSS) [41 are tailored for registration, research, and classification of acute disease cases. EIDSS manages case data, aggregate data with corresponding samples, and laboratory data linked to cases. Overseen by the Communicable Diseases Department of NCDC, this system collects and distributes data entered by epidemiologists in public health centers; creates notifications on disease events in near real-time; and provides access from desktop, web, and mobile devices, allowing secure linkage for diverse users. EIDSS provides data to WHO's Computerized Information System on Infectious Diseases (CISID) [42] via a transfer module and uses an open architecture approach to establish authorized data exchanges with other electronic systems, including the hospital-level MoLHSA Health Management Information System (HMIS). The EIDSS network covers Georgia's regional and district public health centers. Moreover, coordinated by MoLHSA and NCDC, sentinel surveillance will be introduced for key populations targeted for prevention, testing, and treatment interventions (e.g., PWID and persons in correctional facilities) [3].

Several challenges impact HCV elimination among PWID [43]. Policies that make injection-drug use a punishable crime serve as a barrier to reaching PWID with prevention services. The necessity of covering part

Figure 2. If increasing diagnosis and treatment is not coupled with prevention of further transmission, $\mathrm{HCV}$ disease will not end by 2030 [16].

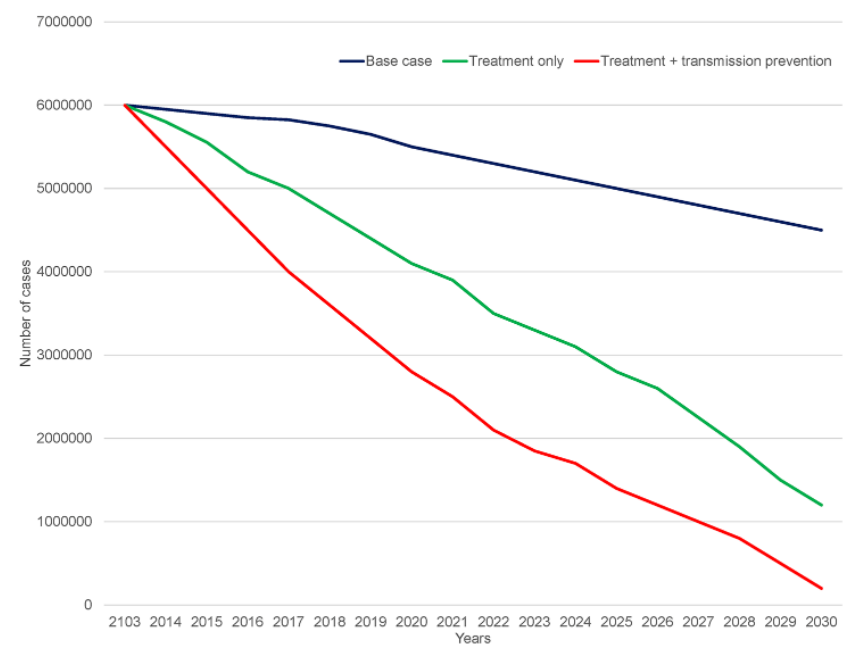

Blue: the base cases, Red: decline in number if only diagnosis and treatment are upgraded, Green: decline in number if upgraded diagnosis and treatment are coupled with prevention of transmission. 
of the expenses of OST and NSP programs limits access to the service. Financial problems will be augmented when funds provided by GFATM will come to the end. Unfortunately, no PWID service is provided to prisoners who constitute an important risk group and service provided for women is poor [8].

Profit-based management of blood establishments and decentralization of blood transfusion services [34] are problems interfering with elimination of TTIs. Further, only 12 of the 18 licensed blood establishments are currently engaged in the SSBP. However, because no effective mechanisms are in place to enforce modification of a state license, the six blood banks can continue to produce blood for use in hospitals. Definitely, all other components of a quality-control system are in need of improvement [3].

Preventing HCV infection is more feasible than complete eradication, therefore effective scale-up of IC implementation is a must. At a healthcare facility level, many hospitals have not established IC programs and many medical staff remain unfamiliar with existing national IC regulations, standards, and guidelines. Additionally, at a community- level, a wide-reaching informational campaign is needed to promote public adherence to safe practices during aesthetic and cosmetic procedures, e.g. tattoo. Beauty salons ought to be licensed and monitored [3].

Future challenges common to both countries are possibility of treatment failure [22] including the emergence of resistance- associated variants (RAVs) and assessment of the importance of occult HCV infection in a background of high rates of $\mathrm{HCV}$ prevalence.

\section{Discussion}

In spite of the great differences between Egypt and Georgia regarding area, population and cultural background, the very high incidence of $\mathrm{HCV}$ infection exists in both. The social spectrum of HCV in Georgia is quite different from Egypt. In Georgia most cases are clustered within PWID which renders HCV a stigmatized disease. Thus, sociocultural factors play a key role in all stages of the disease from transmission of infection to the impact of the disease on the patient. In order to overcome such hurdles Georgia is working hard to establish an environment free of stigma, discrimination, and human rights violations associated with hepatitis $\mathrm{C}$ and drug use. Trials are going on at numerous levels including the Ministry of Internal Affairs, government and nongovernment agencies and healthcare workers. Moreover, preventive actions are intending to support the development of harm-reduction programs for PWID with special needs e.g., women, youth, and persons with disabilities [3].

It is well established that nation-wide surveillance is the basic element for designing eradication campaigns. By 2015, Egypt conducted three surveys; 1996, 2008 and 2015 [20]. More importantly, these national studies provided an opportunity to apply established mathematical models to estimate HCV incidence and HCV infection burden in Egypt through 2030 using advanced statistical methods [5]. In Georgia, a population-based survey of hepatitis $\mathrm{C}$ was carried out in 2002 in Tbilisi. In 2015, the wide-ranging survey of hepatitis B and hepatitis C was conducted which provided a clearer picture of prevalence and risk factors. Very recently, co-ordinated by MoLHSA and NCDC, surveillance systems will be modified to enable the analysis of HCV data on individual- rather than aggregate- level which is more useful in developing prevention and intervention strategies [3]. Availability of expertise and effective systems for large-scale national surveillances, coupled with the accessibility of outcome data in the national database helped carrying out accurate surveillances in both countries.

The most recent Egyptian surveillance estimates of $10 \% \mathrm{HCV}$ infection among adults and $0.4 \%$ in children; nearly equal to 10 million people which constitute an enormous economic burden. The direct healthcare cost of HCV infection has been estimated to be US\$ 670 million, and the indirect economic impact of disability to be US\$ 3.7 billion, close to $1.8 \%$ of the gross domestic product (GDP) similar to diabetes mellitus and cardiovascular diseases cost in the US [44]. Curing a patient is expected to save $\sim$ US $\$ 10,000$ for the next 15 years [5]. The intangible costs to society and families have not been assessed.

An important component of the Egyptian HCV survey is the estimation of $\mathrm{HCV}$ infection among children. Generally, infected children are mostly asymptomatic, with normal ALT levels. In countries where the $\mathrm{HCV}$ burden is massive, it is important to precisely identify the incidence and risk factors for acquiring $\mathrm{HCV}$ in children. Early management is anticipated to reduce morbidity levels and improve the quality of life. Moreover, it alleviates the associated social stigma, a source of substantial caregiver stress, and modulates the psychosocial status of patients and their families. It is expected that opposing the infection sooner will decrease the risk of transmission to the population at large.

After the launching of DAAs, negotiation carried out by both countries worked towards making these agents affordable for HCV treatment. The Egyptian 
agreement as regards DAAs was not the first achievement towards progressively reducing the price of HCV therapy. It was preceded in 2004, by the successful negotiations for cost reduction of the SOC regimen. As with minimizing expenses of pegIFN/R therapy due to local manufacturing [6], the price of DAAs was triggered down by the local availability of several generic biosimilars. Next, brands have been phased out in favor of local generics which are equally effective [45].

Prompt screening and diagnosis of HCV impact the success of the HCV fighting campaigns. What's most concerning is that the majority of people with $\mathrm{HCV}$ aren't aware of their infection. To reduce the numbers of people dying from liver disease and prevent people from unknowingly passing on their infection, it's vital to increase access to testing. HCV screening programs in Georgia began in January 2015, before the launch of the program, and screening services continued to be provided at various settings at no cost [27]. By December 2015, HCV testing for pregnant women had been introduced into the Maternal and Child Care program [3]. Between January 2015-December 2016, a total of $472,890 \mathrm{HCV}$ screening tests were conducted which clarifies the prevalence situation in this country [27].

The human resource capabilities for patient treatment and care contributed to the success in both countries. Egyptian hepatologists have extensive experience due to the high prevalence of liver diseases in the country. Although not conclusive, an outstanding example is the success story in the management of schistosomiasis, and its complications which resulted in complete eradication of the disease. It is interesting to know that schistosomiasis was endemic in Egypt since ancient times. Infection was diagnosed in mummies 3000,4000 and 5000 years old [46]. Georgian familiarity with HIV prevention and control programs was a major contributor to the success of the Georgian program. Georgia's achievements in HIV treatment, care and prevention represent the best practice on a Global scale. International experts describe the Georgian model of HIV treatment and care delivery as exemplary and regard it as the best among countries of former Soviet Union (FSU) and one of the best, if not the best, among low and middle income countries worldwide [21].

\section{Conclusion}

The fruitful models of Egypt and Georgia should be profoundly broken down to decide the explanations behind their prosperity and the probability of their capacity to be exchanged or adjusted to different settings. The attention on preventive actions (e.g., IC, blood safety, and harm reduction) as treatment should be kept up. A critical component of HCV battling programs is the research for solving present and future difficulties.

\section{Acknowledgements}

Acknowledgement is due to Moheb Youssef, M.D., M.Sc. (Ortho). Associate professor and chair, Science Department, West Coast University, Ontario, CA, USA for editing the whole manuscript

\section{References}

1. Rao MR, Naficy AB, Darwish MA, Darwish NM, Schisterman E, Clemens JD, Edelman R (2002) Further evidence for association of hepatitis $\mathrm{C}$ infection with parenteral schistosomiasis treatment in Egypt. BMC Infect Dis 2: 29.

2. Amer FA, Gohar M, Yousef M (2015) Epidemiology of hepatitis $\mathrm{C}$ virus infection in Egypt. Int J Trop Dis Health 7: 119-131.

3. Georgia's Ministry of Labour, Health and Social Affairs, the National Centre for Disease Control and Public Health, U.S. Centers for Disease Control and Prevention, Technical Advisory Group (2018) "Strategic plan for the elimination of hepatitis C virus in Georgia, 2016-2020". Available: http://www.moh.gov.ge/uploads/files/2017/akordeoni/failebi/ Georgia_HCV_Elimination_Strategy_2016-2020.pdf. Accessed 27 January 2018

4. Egyptian Ministry of Health and Population (2014) Plan of Action for the Prevention, Care \& Treatment of Viral Hepatitis, Egypt, 2014-2018, Available: http://www.emro.who.int/images/stories/egypt/VH_Plan_of Action_FINAL_PRINT1.pdf. Accessed 29 April 2017

5. Gomaa A, Naglaa Allam N, Elsharkway A, El Kassas M, Waked I (2017) Hepatitis C infection in Egypt: prevalence, impact and management strategies. Hepat Med 9: 17-25.

6. El-Akel W, El-Sayed MH, El Kassas M, El-Serafy M, Khairy M, Elsaeed K, Kabil K, Hassany M, Shawky A, Yosry A, Shaker MK, ElShazly Y, Waked I, Esmat G, Doss W (2017) National treatment programme of hepatitis C in Egypt: Hepatitis C virus model of care. J Viral Hepat 24: 262-267

7. Gvinjilia L, Nasrullah M, Sergeenko D, Tengiz Tsertsvadze T, Kamkamidze G, Butsashvili M, Gamkrelidze A, Imnadze P, Kvaratskhelia V, Chkhartishvili N, Sharvadze L, Drobeniuc J, Hagan L, Ward JW, Morgan J, Averhoff F (2016) National progress toward hepatitis C elimination - Georgia, 20152016. MMWR 65: 1130-1135

8. Bemoni Public Union, Curatio International Foundation (2015) Population size estimation study among injecting drug users in Georgia, 2014: Study report. Available: http://curatiofoundation.org/wpcontent/uploads/2016/05/PWIDs-PSE-Report-2015_ENG.pdf. Accessed 30 December 2016.

9. Karchava M, Waldenström J, Parker M, Hallack R, Sharvadze L, Gatserelia L, Chkhartishvili N, Dvali N, Dzigua L, Dolmazashvili E, Norder H, Tsertsvadze T (2015) High incidence of the hepatitis $\mathrm{C}$ virus recombinant $2 \mathrm{k} / \mathrm{lb}$ in 
Georgia: Recommendations for testing and treatment. Hepatol Res 45: 1292-1298.

10. Demetriou VL, Kyriakou E, Kostrikis LG (2011) Near-full genome characterization of two natural intergenotypic $2 \mathrm{k} / 1 \mathrm{~b}$ recombinant hepatitis $C$ virus isolates. Adv Virol 2011: 1-7.

11. Kamel MA, Ghaffar YA, Wasef MA, Wright M, Clark LC, Miller FD (1992) High HCV prevalence in Egyptian blood donors. Lancet 340: 427.

12. National Committee for the Control of Viral Hepatitis, Ministry of Health and Population (2008) Egyptian national control strategy for viral hepatitis 2008-2012. Available: https://www.researchgate.net/profile/Imam Waked/publicatio n/267748513_Optimal_Management_of_HCV_Genotype_4/li nks/56c5a02708aeeeffa9e76d0b/Optimal-Management-ofHCV-Genotype-4.pdf. Accessed 1 June 2017

13. Milani B, Gaspani S (2013) Pathway to affordable, qualityassured sources of pegylated interferon alpha for treating hepatitis C. GaBI Journal 2: 194-203.

14. El-Zenati F, Way A (2008) Egypt demographic and health survey.

https://dhsprogram.com/pubs/pdf/FR220/FR220.pdf Accessed May 22nd 2017

15. Esmat G, El Raziky M, El Kassas M, Hassany M, Gamil ME (2012) The future for the treatment of genotype 4 chronic hepatitis C. Liver Int 32:146-150.

16. Waked I, Doss W, El-Sayed MH, Estes C, Razavi H, Shiha G, Yosry A, Gamal Esmat (2014) The current and future disease burden of chronic hepatitis C virus infection in Egypt. Arab J Gastroenterol 15: 45-52.

17. Elbaz T, El-Kassas M, Esmat G (2015) A new era for management of chronic hepatitis $\mathrm{C}$ virus using direct antiviral agents: A review. J ADV Res 6: 301-310

18. Hepatitis C Society (2016) Harvoni cost in US, Canada, India (Updated), UK, Egypt and Europe. Available: http://esofosbuvir.com/harvoni-cost-in-usa-canada-europeegypt-india/. Accessed 30 January 2018.

19. El-Fishawy H, Saadi G, Hassaballa M, Hussein M, Doss W, Ragab G, Barsoum R (2016) Antiviral treatment prioritization in HCV-infected patients with extrahepatic manifestations An Egyptian perspective. J Adv Res 7: 391-402

20. Kandeel A, Genedy M, El-Refai S, Anna L. Funk AL, Aand F, Talaat M (2017) The prevalence of hepatitis $C$ virus infection in Egypt 2015: implications for future policy on prevention and treatment. Liver Int 37: 45-53.

21. National Center for Disease Control and Public Health. Global AIDS Response Progress Report- Georgia. Country Progress Report. Reporting Period January 2012- December 2013. Available:

http://www.unaids.org/sites/default/files/country/documents/ GEO narrative report 2014.pdf. Accessed: 14 February 2018

22. Zaller N, Nelson KE, Aladashvili M, Badridze N, del Rio C, Tsertsvadze T (2004) Risk factors for hepatitis C virus infection among blood donors in Georgia. Eur J Epidemiol 19: $547-553$

23. Global Fund (2014) Global Fund and Hepatitis C Treatment, 32nd Board Meeting. Available: https://www.theglobalfund.org/media/4141/bm32_22hepc_report_en.pdf. Accessed: 15 February 2018.

24. Médecins du Monde France (2016) "High prevalence of hepatitis $\mathrm{C}$ infection and important treatment needs among people who inject drugs, Tibilis, Georgia. Available: https://issuu.com/medecinsdumonde/docs/hcv-georgia afd. Accessed 15 February 2018.
25. Mitruka K, Tsertsvadze T, Butsashvili M, Gamkrelidze A, Sabelashvili P, Adamia E, Chokheli M, Drobeniuc J, Hagan L, Harris AM, Jiqia T, Kasradze A, Ko S, Qerashvili V, Sharvadze L, Tskhomelidze I, Kvaratskhelia V, Morgan J, Ward LW, Averhoff F (2015) Launch of a nationwide hepatitis C elimination program - Georgia. MMWR 64: 753-757

26. Vallet-Pichard A, Mallet V, Nalpas B, Verkarre V, Nalpas A, Dhalluin-Venier V, Fontaine H, Pol S (2007) FIB-4: an inexpensive and accurate marker of fibrosis in HCV infection. Comparison with liver biopsy and fibrotest. Hepatology 46: $32-36$.

27. Nasrullah M, Sergeenko D, Gvinjilia L, Gamkrelidze A, Tsertsvadze T, Butsashvili M, Metreveli D, Sharvadze L, Alkhazashvili M, Shadaker S, Ward JW, Morgan J, Averhoff F (2017) The role of screening and treatment in national progress toward hepatitis C elimination - Georgia, 20152016. MMWR 66: 773-776

28. Talaat M, El-Oun S, Kandeel A, Abu-Rabei W, Bodenschatz C, Lohiniva A, Hallaj Z, Mahoney F (2003) Overview of injection practices in two governorates in Egypt. Trop Med Intel Health 8: 234-241.

29. Talaat M, Kandeel A, Rasslan O, Mahoney FJ (2006) Evolution of infection control in Egypt: achievements and challenges. Am J Infect Control 34: 193-200

30. El Sayed N, Kandeel A, Genedy M, Esmat G, Doss W, El Sayed M, Al Gasseer N, Eltantawy N, Hassan El Bushra, Talaat M, Hande Harmanci H, Fontanet A, Bernier A, Tohme RA, Averhoff F (2012) Progress toward prevention and control of hepatitis C virus infection - Egypt, 2001-2012. MMWR 61: $545-549$

31. World Health Orgnization (2015) World Hepatitis Day in Egypt focuses on hepatitis $\mathrm{B}$ and $\mathrm{C}$ prevention. Available: http://www.emro.who.int/media/news/world-hepatitis-day-inegypt-focuses-on-hepatitis-b-and-c-prevention.html. Accessed 7 May 2017

32. Treloar C, Rance J, Backmund M (2013) Understanding barriers to hepatitis $\mathrm{C}$ virus care and stigmatization from a social perspective. Clin Infect Dis 57 Suppl 2: 51-55.

33. Gogia M (2015) Assessing risky behavior of PWIDs in Georgia - Comparable analyses of two samples. J Hum Virol Retrovirol 2: 45.

34. Stvilia K, Tsertsvadze T, Sharvadze L, Aladashvili M, del Rio C, Kuniholm MH, KE Nelson (2006) Prevalence of hepatitis C, HIV, and risk behaviors for blood-borne infections: a population-based survey of the adult population of T'bilisi, Republic of Georgia. J Urban Health 83: 289-298.

35. Kandelaki G, Butsashvili M, Geleishvili M, Avaliani N, Macharashvili N, Topuridze M, Del Rio C, Blumberg HM, Tsertsvadze T (2011) Nosocomial infections in Georgia; a retrospective study of microbiological data from four major tertiary care hospitals in Tbilisi, capital of Georgia. Infect Control Hosp Epidemiol 32: 933-34.

36. Kalinina O, Norder H, Mukomolov S, Magnius LO (2002) A natural intergenotypic recombinant of hepatitis $\mathrm{C}$ virus identified in St. Petersburg. J Virol 76: 4034-4043.

37. Moreau I, Hegarty S, Levis J, Sheehy P, Crosbie O, KennyWalsh E, Fanning LJ (2006) Serendipitous identification of natural intergenotypic recombinants of hepatitis $\mathrm{C}$ in Ireland. Virol J 3: 95.

38. Tallo T, Norder H, Tefanova V, Krispin T, Schmidt J, Ilmoja M, Orgulas K, Pruunsild K, Priimägi L, Magnius LO (2007) Genetic characterization of hepatitis $\mathrm{C}$ virus strains in Estonia: 
fluctuations in the predominating subtype with time. J Med virol 79: 374-382.

39. Kurbanov F, Tanaka Y, Avazova D, Khan A, Sugauchi F, Kan N, Sugauchi F, Kan N, Kurbanova-Khudayberganova D, Khikmatullaeva A, Musabaev E, Mizokamiet M (2008) Detection of hepatitis $C$ virus natural recombinant RF1 2k/1b strain among intravenous drug users in Uzbekistan. Hepatol Res 38: 457-464.

40. Ramiere C, Tremeaux P, Caporossi A, Trabaud M, Lebosse F, Bailly F, Bailly F, Thélu MA, Nana J, Leroy V, Morand P, André P, Larrat S (2014) Recent evidence of underestimated circulation of hepatitis $\mathrm{C}$ virus intergenotypic recombinant strain RF2k/1b in the Rhone-Alpes region, France, January to August 2014: implications for antiviral treatment. Euro Surveill 19: 1-

41. Wahl TG, Burdakov A, Ukharov AO, Zhilokov AK (2012) Electronic integrated disease surveillance system and pathogen asset control system. Onderstepoort J Vet Res 79: 455.

42. World Health Organization (WHO) / Europe (2013) Centralized information system for infectious diseases (CISID). Available: http://www.thehealthwell.info/node/551473. Accessed: $13 \mathrm{t}$ February 2018.

43. Chkhartishvili N, Sharvadze L, Chokoshvili O, Bolokadze N, Rukhadze N, Kempker RR, Gamkrelidze A, DeHovitz JA, Rio CD, Tsertsvadze1 T (2014) Mortality and causes of death among HIV-infected individuals in the country of Georgia: 1989-2012. AIDS Res Hum Retroviruses 30: 560-566.

44. Abdel-Kareem M, Abdel-Razek W, Abdel-Sameea E, Abuzeid M, Gomaa A, Osman W, Razavi H, Zaghla H, Waked I (2015) Economic burden of hepatitis $\mathrm{C}$ in Egypt: the future impact of highly effective therapies. Aliment Pharmacol Ther 42: 696706.

45. Salama H, Zekri A, Medhat E, Al Ansary M, Zienab Zakaria Z (2016) Effect of sofosbuvir, brand drug (Sovaldi) versus generic (MPI Viropack) in treating chronic HCV genotype 4 infection among Egyptian patients. ECGDS 1: 56-61.

46. M. Ruffer (1910) Note on the presence of "Bilharzia haematobia" in Egyptian mummies of the twentieth dynasty $\mathrm{Br}$ Med J 1 1-16.

\section{Corresponding author}

Professor Fatma Amer, MBBCh, MSc, PhD

Emeritus Professor

Zagazig Faculty of Medicine

9A Road 275, New Maadi

Cairo, Egypt

Phone: 00201223134810

Email: egyamer@yahoo.com

Conflict of interests: No conflict of interests is declared. 